\title{
Penerapan Metode AHP Dalam Mencari Jurusan Yang Paling Diminati
}

\author{
Narti $^{1}$, Ahmad Yani $^{2}$, Sriyadi $^{3}$ \\ ${ }^{1}$ Sistem Informasi, Sekolah Tinggi Manajemen Informatika dan Komputer Nusa Mandiri \\ Indonesia \\ ${ }^{2}$ Sistem Informasi, Universitas Bina Sarana Informatika \\ Indonesia \\ ${ }^{3}$ Sistem Informasi, Universitas Bina Sarana Informatika \\ Indonesia
}

E-mail:narti.nrx@nusamandiri.ac.id,ahmad.amy@bsi.ac.id,sriyadi.sry@bsi.ac.id

\section{Abstract}

The availability of a choice of majors in SMA makes various motivations and the basic reasons for students to choose and take the study program they will study later. This research was made in order to know the appropriate study program / department in the consideration of students in terms of the students' basic reasons for choosing a major. The research was conducted by distributing questionnaires to 41 respondents, and the model used was the AHP (Analytical Hierarchy Process) model, which is a multicriteria decision-making method. With this research, it is expected that there will be a change in the mindset of students in choosing the department so that they are not wrong in determining the chosen department. The results showed that there were three main criteria used, namely Interest, Role of Parents and Opportunities, where it was found that interest was the highest criterion in the selection of a department, namely $47 \%$ or 0.47 and in the process of selecting the Department there were three alternatives, namely Accounting, Multimedia, and Computer and Network Engineering that produces accounting as the most important alternative with the highest priority weight of $37 \%$ or 0.37 .

Keywords: AHP method; Search for majors

\begin{abstract}
Abstrak
Tersedianya pilihan jurusan di SMA membuat beragam motivasi serta alasan dasar dari siswa dalam memilih dan mengambil program studi yang nanti dipelajarinya. Penelitian ini dibuat agar diketahuinya program studi/ jurusan yang sesuai pada pertimbangan siswa yang ditinjau dari alasan dasar siswa dalam memilih jurusan. Penelitian dilakukan dengan cara penyebaran kuesioner ke 41 responden, dan model yang digunakan adalah model AHP (Analytical Hierarchy Process) yang merupakan sebuah metode pengambilan keputusan multikriteria. Dengan penelitian ini diharapkan adanya perubahan pola pikir siswa dalam memilih Jurusan agar tidak salah dalam menentukan Jurusan yang dipilih. Hasil penelitian menunjukkan ada tiga kriteria utama yang digunakan yaitu Minat, Peran Orang Tua dan Peluang, dimana didapatkan bahwa Minat menjadi kriteria tertinggi pada pemilihan Jurusan yaitu 47\% atau sebesar 0,47 serta dalam proses pemilihan Jurusan terdapat tiga alternatif yaitu Akuntansi, Multimedia, serta Teknik Komputer dan Jaringan yang menghasilkan Akuntansi sebagai alternatif terpenting dengan bobot prioritas tertinggi $37 \%$ atau sebesar yaitu 0,37 .
\end{abstract}

Kata Kunci: Metode AHP; Mencari Jurusan 


\section{Introduction}

Dalam kurikulum yang berlaku di Indonesia, calon siswa SMA/SMK yang akan mendaftar sekolah pasti menghadapi proses pemilihan jurusan. Berdasarkan hal tersebut, calon siswa harus mampu dalam menilai minat, bakat dan kemampuannya agar dapat tepat memilih jurusan yang akan diambilnya. Pengambilan program studi atau jurusan oleh calon siswa SMA/SMK merupakan langkah pertama dari penentuan karirnya ke depan. Kadang-kadang tidak sedikit calon siswa yang mengambil jurusan karena mengikuti teman. Peran orang tua juga sangatlah penting. Orang tua diharapkan mampu mengarahkan anak mereka dalam mengambil program studi yang sesuai dengan minat, bakat dan kemampuan mereka. Pada jenjang SMA/SMK, siswa ada dalam masa menuju dunia pendidikan tinggi untuk membentuk integritas karir yang didambakannya. Banyak sekali kasus dimana siswa mengalami kebingungan dan stres sehingga dalam pemilihan Jurusan sering membuat siswa mengambil keputusan sendiri dan singkat dalam menentukan pilihan.

Alasan yang mendasari siswa sekolah menengah kejuruan dalam memilih Jurusan antara lain: 1) Minat dari siswa. 2) Nilai yang disyaratkan pada masing-masing Jurusan. 3) Saran dari orang tua. 4) Pertimbangan ranking. (Harahap, 2015)

Sebuah SMK di Tangerang, merupakan sebuah sekolah menengah kejuruan di bidang bisnis manajemen dan teknologi informasi dan komunikasi menawarkan kepada siswanya tiga macam jurusan dimana setiap siswa diwajibkan memilih salah satu dari tiga jurusan tersebut yang terdiri atas program keahlian Akuntansi, Multimedia, dan Teknik Komputer dan Jaringan. Proses penjurusan dilakukan berdasarkan minat siswa, namun dalam pelaksanaannya sering terjadi keadaan dimana jurusan yang dipilih siswa kurang sesuai dengan kemampuan yang sebenarnya dimiliki serta terjadinya ketidakmerataan antara jumlah peminat masing-masing Jurusan. Dalam rangka meningkatkan tingkat kesesuaian antara kemampuan siswa dan program yang dipilih maka perlu diadakan perbaikan tentang cara pandang siswa dalam tentukan program studi yang hendak dipilih siswa. metode yang digunakan dalam mendukung pengambilan keputusan ialah AHP (Analytical Hierarchy Process).

\section{Materials and Methods}

\subsection{Metode AHP (Analytical Hierarchy Process)}

Model AHP adalah satu metode pendukung keputusan yang bisa menguraikan masalah banyak faktor atau banyak kriteria yang kompleks jadi suatu hirarki, hirarki diartikan sebagai suatu perwakilan dari sebuah masalah yang luas di sebuah urutan banyak level dimana level kesatu adalah yang diiringi level faktor, kriteria, sub kriteria, dan selanjutnya ke bawah hingga level alternatif akhir. Akhir dalam tahapan AHP ialah prioritas pada alternatif (Nugraha, Abdillah, \& Ilyas, 2018).

Menurut (Marbun, Sagala, Rahayu, 2018) Sistem Pendukung Keputusan merupakan pengembangan lebih lanjut dari system informasi manajementer komputerisasi (Computerezed Management Information System), dibuat dengan sedemikian rupa agar bersifat user friendly dengan pemakainya. 
Sumber : (Pratiwi, 2016)

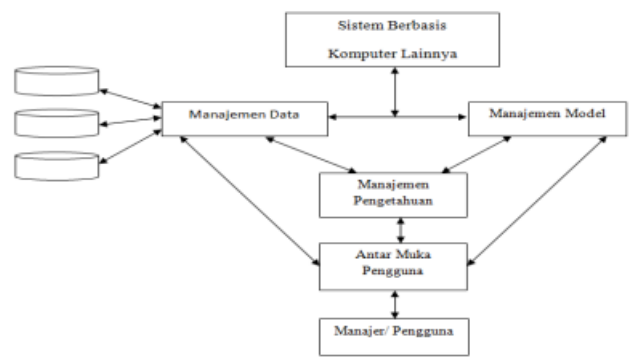

Sumber : (Fitriyani, 2016)

Gambar 1. Skema Sistem Pendukung Keputusan

\subsection{Langkah - Langkah AHP}

Pada dasarnya step yang perlu diperhatikan pada metode AHP (Pratiwi, 2016), antara lain:

\section{Membuat Hierarki}

problem yang akan dieksekusi, diurai menjadi unsurnya, yaitu kriteria dan alternatif, lalu ditata menjadi struktur hierarki seperti dibawah ini:

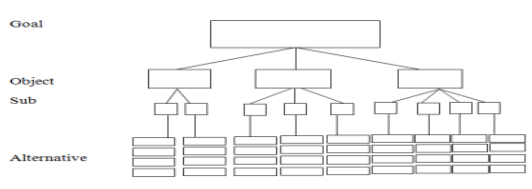

Gambar 2. Struktur Hierarki AHP

\section{Penilaian Kriteria dan Alternatif}

Agar berbagai masalah yang ada, skala satu hingga sembilan merupakan skala terbaik untuk mengungkapkan asumsi. Value dan arti asumsi Kualitatif pada skala perbandingan.

Komparasi dilaksanakan berdasarkan peraturan pembuat keputusan dengan melakukan penilaian jenjang kepentingan sebuah bagian terhadap bagian lain. Misal A1, A2, dan A3. Maka susunan berbagai elemen yang komparasi tersebut akan terlihat seperti dalam tabel matriks dibawah:

Tabel 2. Contoh Matriks Perbandingan Berpasangan

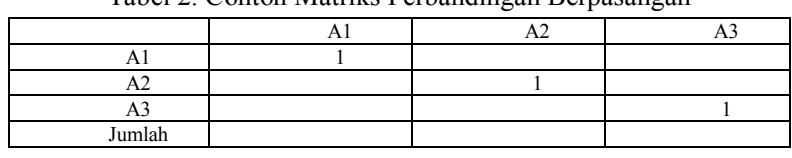

\section{Penentuan Prioritas}

Dalam tiap kriteria, harus dibuat komparasi berpasangan (Pairwise Comparisons). value komparasi relatif selanjutnya mengolahnya agar mendapatkan penentuan peringkat alternatif dalam semua alternatif.

\section{Konsistensi Logis}

Konsistensi punya 2 arti. kesatu, hal-hal yang serupa bisa diklasifikasikan sesuai pada keseragaman serta relevansi. berikutnya, menyangkut tingkat relasi antar objek yang mulaikan pada kriteria tertentu.

Pada dasarnya step yang harus dicermati pada metode AHP (Pratiwi, 2016), diantaranya:

1. menerangkan problem dan memutuskan jalan keluar yang tepat.

2. Menetapkan elemen utama.

3. Membuat komparasi berpasangan, yaitu mengkomparasi bagian/elemen dengan cara berpasang sesuai kriteria yang telah diberikan.

4. Larik bilangan berpasangan diisi dengan bilangan untuk merepresentasikan kepentingan relatif pada suatu elemen terhadap elemen yang lainnya.

5. Sintesis.

Sangat perlu sekali untuk tahu seberapa baik konsistensi yang ada sebab tidak menginginkan keputusan berdasarkan pertimbangan dengan ketetapan yang minim dalam membuat decision.

\subsection{Metode Pengumpulan Data}

Ada empat tahapan pada penelitian ini menurut (Sulistyowati Nur, Budiawan \& Ningtyas Arum, 2018) yang dilakukan yaitu:

1. Pengamatan Langsung (Observasi)

Dalam penelitian ini dilakukan pengamatan pada data-data terkait 
dengan penelitian, seperti data siswa yang memilih program studi di sebuah SMK di Tangerang.

2. Wawancara (Interview)

Agar dapat lengkap data-data yang dibutuhkan peneliti melakukan tanya jawab secara langsung dengan siswa dari kalangan pemilih program studi.

3. Angket (Kuesioner)

Peneliti menyebarkan lembar kuesioner kepada responden yang memilih program studi pada sebuah SMK di Tangerang.

4. Studi Pustaka

Pengumpulan data dengan studi pustaka adalah dengan cara mencari referensi dari buku-buku, jurnal maupun literature sebagai penunjang untuk kelancaran penelitian.

\subsection{Populasi}

Menurut (Asra, 2014) Populasi merupakan kelompok dari seluruh unsur atau elemen atau unit pengamatan. Populasi menurut (Sujarweni, 2014) merupakan semua jumlah yang terdiri dari subjek atau objek yang memiliki karakter dan kualitas yang dibuat oleh peneliti dan kemudian diambil kesimpulan. Maka populasi dari penelitian ini adalah siswa dari sebuah SMK di Tangerang berjumlah 41 orang.

\subsection{Sampel Penelitian}

Menurut (Siregar, 2014) Sebuah prosedur pengambilan data, yang hanya sebagian dari populasi saja yang diambil dan digunakan dalam menentukan ciri dan sifat yang dikehendaki dari suatu populasi adalah sample.

Menurut (Indarti, Deny Pribadi, 2017) Sampel merupakan sebagian contoh dari populasi penelitian yang bisa mewakilkan populasi. Responden yang diambil dalam penelitian ini responden yang sudah menjadi siswa pada sebuah SMK di Tangerang sekaligus populasi, maka sampel yang akan diambil sebagai penelitian diambil dan ditentukan dengan rumus Slovin dengan tingkat kepercayaan 99\% dan tingkat error $1 \%$ adalah

$$
\mathrm{n}=\frac{N}{1+\left(N \times e^{2}\right)}
$$

Dimana: $\mathrm{n}=$ Ukuran sampel

$$
\mathrm{N}=\text { Populasi }
$$

$\mathrm{e}=$ Presentase kelonggaran ketidakterikatan karena kesalahan pengambilan sampel yang masih diinginkan. Maka dapat diperoleh perhitungan untuk sampel peneltian yakni:

$$
\begin{aligned}
& \mathrm{n}=\frac{41}{1+\left(41 \times 0.01^{2}\right)} \\
& =41 \text { Orang }
\end{aligned}
$$

Jadi, sampel penelitian untuk populasi 41 orang dan tingkat kepercayaan $99 \%$ adalah 41 orang.

\section{Results and Discussion}

berdasarkan pengolahan data dalam memilih/ mengambil jurusan/ program studi melalui perbandingan alternatif Minat, maka berikut proses perhitungannya:

Tabel 3. Penjumlahan Nilai Kolom Minat

\begin{tabular}{|c|c|c|c|}
\hline Alternatif & Akuntansi & Multimedia & TKJ \\
\hline Akuntansi & 1.000 & 1.107 & 2.682 \\
\hline Multimedia & 0.904 & 1.000 & 1.539 \\
\hline TKJ & 0.373 & 0.650 & 1.000 \\
\hline Total & 2.277 & 2.757 & 5.221 \\
\hline
\end{tabular}

Tabel 4. Normalisasi Minat

\begin{tabular}{|c|c|c|c|}
\hline Alternatif & Akuntansi & Multimedia & TKJ \\
\hline Akuntansi & 0.439 & 0.402 & 0.514 \\
\hline Multimedia & 0.397 & 0.363 & 0.295 \\
\hline TKJ & 0.164 & 0.236 & 0.192 \\
\hline \multicolumn{2}{|c|}{ Vektor Eigen } & & 1.000 \\
\hline
\end{tabular}

Tabel 5. Nilai Rata- Rata Minat

\begin{tabular}{|c|c|c|c|c|}
\hline Alternatif & Akuntansi & Multimedia & TKJ & Rata-rata \\
\hline Akuntansi & 0.439 & 0.402 & 0.514 & 0.452 \\
\hline Multimedia & 0.397 & 0.363 & 0.295 & 0.352 \\
\hline TKJ & 0.164 & 0.236 & 0.192 & 0.197 \\
\hline \multicolumn{5}{|r}{}
\end{tabular}

Dalam pengolahan data pada pemilihan program studi dari perbandingan 
alternatif Peran Orang Tua, maka berikut proses perhitungannya:

Tabel 6. Penjumlahan Nilai Kolom Peran Orang Tua

\begin{tabular}{|c|c|c|c|}
\hline Alternatif & Akuntansi & Multimedia & TKJ \\
\hline Akuntansi & 1.000 & 0.732 & 0.567 \\
\hline Multimedia & 1.365 & 1.000 & 1.127 \\
\hline TKJ & 1.764 & 0.967 & 1.000 \\
\hline Total & 4.129 & 2.699 & 2.694 \\
\hline
\end{tabular}

Tabel 7. Normalisasi Peran Orang Tua

\begin{tabular}{|c|c|c|c|}
\hline Alternatif & Akuntansi & Multimedia & TKJ \\
\hline Akuntansi & 0.242 & 0.271 & 0.210 \\
\hline Multimedia & 0.331 & 0.371 & 0.418 \\
\hline TKJ & 0.427 & 0.358 & 0.371 \\
\hline \multicolumn{3}{|c|}{ Vektor Eigen } & 1.000 \\
\hline
\end{tabular}

Tabel 8. Nilai Rata- Rata Peran Orang Tua

\begin{tabular}{|c|c|c|c|c|}
\hline Alternatif & Akuntansi & Multimedia & TKJ & Rata-rata \\
\hline Akuntansi & 0.242 & 0.271 & 0.210 & 0.241 \\
\hline Multimedia & 0.331 & 0.371 & 0.418 & 0.373 \\
\hline TKJ & 0.427 & 0.358 & 0.371 & 0.385 \\
\hline
\end{tabular}

Dari hasil oleh data dalam memilih program studi/ jurusan berdasarkan perbandingan alternatif Peluang, maka berikut proses perhitungannya:

Tabel 9. Penjumlahan Nilai Kolom Peluang

\begin{tabular}{|c|c|c|c|}
\hline Alternatif & Akuntansi & Multimedia & TKJ \\
\hline Akuntansi & 1.000 & 1.068 & 0.749 \\
\hline Multimedia & 0.936 & 1.000 & 1.116 \\
\hline TKJ & 1.335 & 0.560 & 1.000 \\
\hline Total & 3.271 & 2.628 & 2.865 \\
\hline
\end{tabular}

Tabel 10. Normalisasi Peluang

\begin{tabular}{|c|c|c|c|}
\hline Alternatif & Akuntansi & Multimedia & TKJ \\
\hline Akuntansi & 0.306 & 0.406 & 0.261 \\
\hline Multimedia & 0.286 & 0.381 & 0.390 \\
\hline TKJ & 0.408 & 0.213 & 0.349 \\
\hline \multicolumn{3}{|c|}{ Vektor Eigen } \\
\hline
\end{tabular}

Tabel 11. Nilai Rata- Rata Peluang

\begin{tabular}{|c|c|c|c|c|}
\hline Alternatif & Akuntansi & Multimedia & TKJ & Rata-rata \\
\hline Akuntansi & 0.306 & 0.406 & 0.261 & 0.324 \\
\hline Multimedia & 0.286 & 0.381 & 0.390 & 0.352 \\
\hline TKJ & 0.408 & 0.213 & 0.349 & 0.323 \\
\hline
\end{tabular}

Konsistensi Level 1 Berdasarkan Kriteria

\section{Utama}

$\left[\begin{array}{lll}1.000 & 2.218 & 1.568 \\ 0.451 & 1.000 & 0.542 \\ 0.638 & 1.907 & 1.000\end{array}\right] \mathrm{X}^{\left[\begin{array}{l}0.473 \\ 0.193 \\ 0.334\end{array}\right]}$
$\left[\begin{array}{lll}0.473 & 0.428 & 0.524 \\ 0.213 & 0.193 & 0.175 \\ 0.302 & 0.368 & 0.334\end{array}\right]=\left[\begin{array}{l}1.425 \\ 0.581 \\ 1.004\end{array}\right]$
$\left[\begin{array}{l}1.425 \\ 0.581 \\ 1.000\end{array}\right] \bullet\left[\begin{array}{l}0.473 \\ 0.193 \\ 0.334\end{array}\right]=\left[\begin{array}{l}3.012 \\ 3.012 \\ 3.005\end{array}\right]$

$\lambda$ maksimal $\rightarrow(3.012+3.012+3.005) / 3=$ 3.010

$$
\begin{aligned}
& \mathrm{CI} \rightarrow\left(\frac{3.010-3}{3-1}\right)=0.005 \\
& \mathrm{CR} \rightarrow 0.005 / 0.580=0.008
\end{aligned}
$$

Karena nilai CR $<0,1(10 \%)$ maka "dapat diterima".

Konsistensi Level 2 Berdasarkan Kriteria

\begin{tabular}{|c|c|c|c|c|c|c|}
\hline$[1.000$ & 1.107 & $2.682]$ & {$[0.452]$} & {$[0.452$} & 0.390 & $0.528]$ \\
\hline 0.904 & 1.000 & 1.539 & 0.352 & 0.409 & 0.352 & 0.303 \\
\hline Lo.373 & 0.650 & 1.000 & $\mathrm{X}^{[0.197}$ & 三lo.169 & 0.229 & $0.197]_{=}$ \\
\hline$[1.370]$ & {$[1.3$} & $70]$ & $0.452]$ & {$[3.031]$} & & \\
\hline 1.064 & 1.0 & & 0.352 & 3.022 & & \\
\hline [0.594] & $=0$. & & - & ] & & \\
\hline
\end{tabular}
Minat

$\lambda$ maksimal $\rightarrow(3.031+3.022+3.017) / 3=$ 3.023

$$
\mathrm{CI} \rightarrow\left(\frac{3.023-3}{3-1}\right)=0,012
$$

$\mathrm{CR} \rightarrow 0.012 / 0.580=0.020$

Karena nilai CR $<0,1(10 \%)$ maka "dapat diterima".

Konsistensi Level 2 Berdasarkan Kriteria Peran Orang Tua

$\left[\begin{array}{lll}1.000 & 0.732 & 0.567 \\ 1.365 & 1.000 & 1.127 \\ 1.764 & 0.967 & 1.000\end{array}\right]_{\mathrm{X}}\left[\begin{array}{l}0.241 \\ 0.373 \\ 0.385\end{array}\right]=$
$\left[\begin{array}{lll}0.241 & 0.273 & 0.218 \\ 0.329 & 0.373 & 0.434 \\ 0.425 & 0.361 & 0.385\end{array}\right]=\left[\begin{array}{l}0.732 \\ 1.136 \\ 1.171\end{array}\right]$
$=\left[\begin{array}{l}0.732 \\ 1.136 \\ 1.171\end{array}\right] \cdot\left[\begin{array}{l}0.241 \\ 0.373 \\ 0.385\end{array}\right]\left[\begin{array}{l}3.039 \\ 3.045 \\ 3,041\end{array}\right]$

$\lambda$ maksimal $\rightarrow(3.039+3.045+3.041) / 3=$ 3.042

$$
\begin{aligned}
& \mathrm{CI} \rightarrow\left(\frac{3.042-3}{3-1}\right)=0.021 \\
& \mathrm{CR} \rightarrow 0.021 / 0.580=0.036
\end{aligned}
$$

Karena nilai CR $<0,1(10 \%)$ maka "dapat diterima".

Konsistensi Level 2 Berdasarkan Kriteria Peluang Kerja

$\left[\begin{array}{lll}1.000 & 1.156 & 0.749 \\ 0.865 & 1.000 & 1.116 \\ 1.335 & 0.560 & 1.000\end{array}\right]_{X}\left[\begin{array}{l}0.324 \\ 0.352 \\ 0.323\end{array}\right]=$
$\left[\begin{array}{lll}0.324 & 0.407 & 0.242 \\ 0.280 & 0.352 & 0.360 \\ 0.433 & 0.197 & 0.323\end{array}\right]=\left[\begin{array}{l}0.973 \\ 0.993 \\ 0.953\end{array}\right]$

$=\left[\begin{array}{l}0.973 \\ 0.993 \\ 0.953\end{array}\right] \cdot\left[\begin{array}{l}0.324 \\ 0.352 \\ 0.323\end{array}\right]=\left[\begin{array}{l}3.003 \\ 2.820 \\ 2.949\end{array}\right]$


$\lambda$ maksimal $\rightarrow(3.003+2.820+2.949) / 3=$ 2.924

$\mathrm{CI} \rightarrow\left(\frac{2.924-3}{3-1}\right)=-0,038$

$\mathrm{CR} \rightarrow-0.038 / 0.580=-0.065$

Karena nilai CR $<0,1(10 \%)$ maka "dapat diterima”.

Setelah melakukan proses pengukuran konsistensi kegiatan selanjutnya adalah melakukan sintesis global secara keseluruhan untuk pengambilan keputusan. Prosedurnya ialah:

1. Mengalikan gabungan vektor eigen pada alternatif (level alternatif keputusan) dengan vektor eigen pada kriteria (level kriteria), dan dihasilkan operasi perkalian tersebut selanjutnya disebut sebagai "vektor eigen keputusan".

2. Keputusan yang di ambil adalah keputusan yang mempunyai nilai yang paling besar.

3. $\left[\begin{array}{lll}0.452 & 0.241 & 0.324 \\ 0.352 & 0.373 & 0.352 \\ 0.197 & 0.385 & 0.323\end{array}\right] \mathrm{X}\left[\begin{array}{l}0.473 \\ 0.193 \\ 0.334\end{array}\right]\left[\begin{array}{l}0.369 \\ 0.356 \\ 0.275\end{array}\right]$

Dari vektor eigen keputusan terlihat bahwa:

1. Akuntansi memiliki bobot prioritas tertinggi yaitu 0.369

2. Multimedia memiliki bobot prioritas kedua yaitu 0.356

3. TKJ memiliki bobot prioritas terendah yaitu 0.275

Jika digambarkan dalam bentuk diagram maka dapat dilihat jumlah presentasenya sebgai berikut :

\begin{tabular}{ccc}
\multicolumn{2}{r}{ Pemilihan Program Studi Dengan AHP } \\
& & \\
& TKJ & Multim \\
Akunta & $\mathbf{2 7 \%}$ & edia \\
nsi & & $36 \%$ \\
$37 \%$ & & \\
\end{tabular}

Gambar 3. Diagram Presentase Vektor Eigen Keputusan
Berdasarkan vektor eigen keputusan, maka untuk penentuan pemilihan program studi/ jurusan oleh murid/ siswa melalui Minat siswa itu sendiri dan program studi yang terpilih adalah Akuntansi.

Perhitungan terakhir adalah melakukan pengujian Rasio Konsistensi Hirarki (CRH). Pengujian Rasio Konsistensi Hirarki dilakukan dengan rumus :

$\mathrm{CRH}=\mathrm{CIH} / \mathrm{RIH}$

Dimana :

$\mathrm{CIH} \rightarrow$ CI Kriteria Utama + (vektor eigen kriteria utama) (CI

$=0.005+\left(\begin{array}{lll}0.473 & 0.193 & 0.334\end{array}\right) \times\left(\begin{array}{c}0.012 \\ 0.021 \\ -0.038\end{array}\right)$

$=0.005+(-0.003)$

$=0.002$

$\mathrm{RIH} \rightarrow$ RI Kriteria Utama + (vektor eigen kriteria utama) (RI alternatif)

$=0.008+\left(\begin{array}{lll}0.473 & 0.193 & 0.334\end{array}\right) \times\left(\begin{array}{l}0.580 \\ 0.580 \\ 0.580\end{array}\right)$

$=0.008+0.580$

$=0.588$

$\mathrm{CRH} \rightarrow 0.002 / 0.588=0.003$

Dari perhitungan di atas diperoleh nilai $\mathrm{CRH}<$ dari 0.1 atau kurang dari 10\% maka hirarki secara keseluruhan bersifat konsisten, sehingga kesimpulan dapat diperoleh dapat diterima, artinya keputusan yang di tetapkan dapat diandalkan. Maka, kesimpulan yang di peroleh dari hasil yang telah di peroleh sudah sesuai terhadap hasil hipotesis.

\section{Conclusions}

Berdasarkan hasil analisa dan pengolahan data yang telah dilakukan oleh peneliti, maka dapat diambil beberapa kesimpulan yaitu:

1. Terlihat kalau kriteria Minat adalah faktor yang paling penting bagi siswa karena biasanya siswa memilih program studi berdasarkan keinginan dalam diri sendiri.

2. Dalam penelitian ini terdapat tiga kriteria utama yang di gunakan yaitu Minat, Peran Orang Tua, dan Peluang Kerja, dimana didapatkan bahwa Minat menjadi kriteria tertinggi pada pemilihan program studi dengan bobot $47 \%$.

3. Pada penelitian ini terdapat tiga alternatif yaitu Akuntansi, Multimedia, dan Teknik 
Komputer dan Jaringan, yang menghasilkan Akuntansi sebagai alternatif terpenting dengan bobot prioritas tertinggi yaitu $37 \%$.

\section{References}

[1] Asra, Abuzar. (2014). Esensi Statistik Bagi Kebijakan Publik. Edisi Pertama. Jakarta: InMedia.

[2] Fitriyani. (2016). Sistem Pendukung Keputusan Pemilihan Mahasiswa Berprestasi di STMIK Atma Luhur Pangkalpinang dengan Menggunakan Metode Analytical Hierarchy Process (AHP). Teknosi, 2(2), 109-118.

[3] Harahap, Ahmad Arifin. (2015). Sistem Pendukung Keputusan Penentuan Jurusan Dengan Metode Analytical Hierarchy Process (Studi Kasus : SMK Swasta Kartini Utama Sei Rampah). ISSN: 2301-9425. Medan. Pelita Informatika Budi Darma. Vol. 9, No. 2, Maret 2015:13-20.

[4] Indarti, Deny Pribadi. (2017). Analytical Hierarchy Process Sebagai Penunjang Sistem Pengambilan Keputusan Dalam Penilaian Pelayanan Pada TPU Wilayah Jakarta Utara. ISSN: 2527-6514. Sukabumi. Jurnal Ilmu Pilar Nusa Mandiri. Vol. 13, No. 2, September 2017:187-192.

[5] Marbun, M. Sagala, J. R., Rahayu, D. P. (2018). Menentukan Kelayakan Tunjangan Kesejahteraan Pegawai Menggunakan Metode AHP. ISSN: 2541-3724. Medan. Jurnal Of Informatic Pelita Nusantara. Vol. 3, No. 1, Maret 2018:46-55

[6] Nugraha, R., Abdillah, G., \& Ilyas, R. (2018). Sistem Pendukung Keputusan Penentuan Desa Terbaik Di Kabupaten Cianjur Menggunakan Metode Analytical Hierarchy Process Dan Weighted. ISSN: 2302-3805. Yogyakarta. Jurnal Informasi dan Multimedia. Februari 2018:37-42.
[7] Pratiwi, Heny. (2016). Menentukan Sistem Pendukung Keputusan. Yogyakarta: Deepublish.

[8] Siregar, Syofian. (2014). Statistik Parametrik Untuk Penelitian Kuantitatif. Edisi Kedua. Jakarta: Bumi Aksara.

[9] Sujarweni, Wiratna V. (2014). Metodologi Penelitian. Edisi Pertama. Yogyakarta: Pustaka baru press.

[10] Sulistyowati Nur, D., Budiawan, I., \& Ningtyas Arum, D. (2018). Sistem Pendukung Keputusan Pemilihan Sistem Operasi Windows Pada Desktop Dengan Menggunakan Metode Analytical Hierarchy Process. ISSN: 2527-4864. Jakarta. Jurnal Ilmu Pengetahuan dan Teknologi Komputer. Vol. 3, No. 2, Februari 2018:175-180. 